\title{
The Role of Retinal Vascular Density as a Screening Tool for Ageing and Stroke
}

\author{
Andrea Sprödhuber ${ }^{\mathrm{a}}$ Johannes Wolz ${ }^{\mathrm{a}}$ Attila Budai ${ }^{\mathrm{b}}$ Inga Laumeier \\ Heinrich J. Audebert ${ }^{c}$ Georg Michelson ${ }^{\mathrm{a}, \mathrm{d}, \mathrm{e}}$ \\ ${ }^{a}$ Department of Ophthalmology, Friedrich-Alexander University Erlangen-Nürnberg (FAU), Erlangen, Germany; \\ bPattern Recognition Lab and Graduate School in Advanced Optical Technologies, Friedrich-Alexander University \\ Erlangen-Nürnberg, Erlangen, Germany; ${ }^{C}$ Center for Stroke Research Berlin, Department of Neurology, \\ Charité Berlin, Berlin, Germany; ${ }^{\mathrm{d}}$ Interdisciplinary Center of Ophthalmic Preventive Medicine and Imaging, \\ Friedrich-Alexander University Erlangen-Nürnberg (FAU), Erlangen, Germany; ${ }^{\mathrm{e} T a l k i n g e y e s ~ \& ~ M o r e ~ G m b H, ~ M e d i c a l ~}$ \\ Valley Center, Erlangen, Germany
}

\section{Keywords \\ Retinal vascular density $\cdot$ Ageing $\cdot$ Stroke $\cdot$ Screening \\ - Retinal arteries - Retinal vessels · Telemedicine · \\ Cerebrovascular disease $\cdot$ Transient ischemic attack}

\begin{abstract}
Objectives: To measure the density of retinal vessels from digitized fundus photographs in patients with recent stroke and age-matched controls. To investigate whether the parameter retinal vascular density (RVD) served as a quantitative marker for cerebrovascular events. Methods: Digitized fundus photographs of $n=158$ subjects with stroke or transient ischemic attack within 1 year at the time of examination and $n=1,250$ age-matched controls without any remarkable medical history were examined. Sex, hypertension, and diabetes were considered to be cofactors. Measurement of RVD was performed with a computer-aided image-analyzing program by segmenting automatically all visible retinal vessels and measuring areas of vessels in distinct circles around the optic disk. Results: In controls RVD dwindles with increasing distance from the optic disk. RVD decreased significantly with age $(p=0.000)$. Stroke patients showed significantly lower values of RVD of $-15 \%$ in comparison to age-matched
\end{abstract}

controls. In old subjects, stroke in combination with hypertension is associated with a significant decreased RVD, and in middle-aged subjects diabetes and stroke are associated with a significant decreased RVD $(p=0.01)$. Conclusion: Age and stroke are significant risk factors for decreased RVD. Diabetes and arterial hypertension are additional significant risk factors in patients with stroke with respect to RVD.

(c) 2018 S. Karger AG, Basel

\section{Introduction}

The retina is the only part of the human body that offers the opportunity to in vivo examine the microcirculation of the cerebral circulation in a noninvasive way. It is well known that changes in the retinal vascular system provide a clue to the vascular status of various organs [1]. Population studies have found hypertension, diabetes mellitus, hypercholesterolemia, nicotine abuse, overweight, and physical inactivity to be associated with systemic microvascular damage. Furthermore, the base rate of microvascular alterations was announced to be strongly age related [2-6]. As reported previously, patients who suffered from minor stroke showed a significantly higher

\section{KARGER}

(C) 2018 S. Karger AG, Basel 

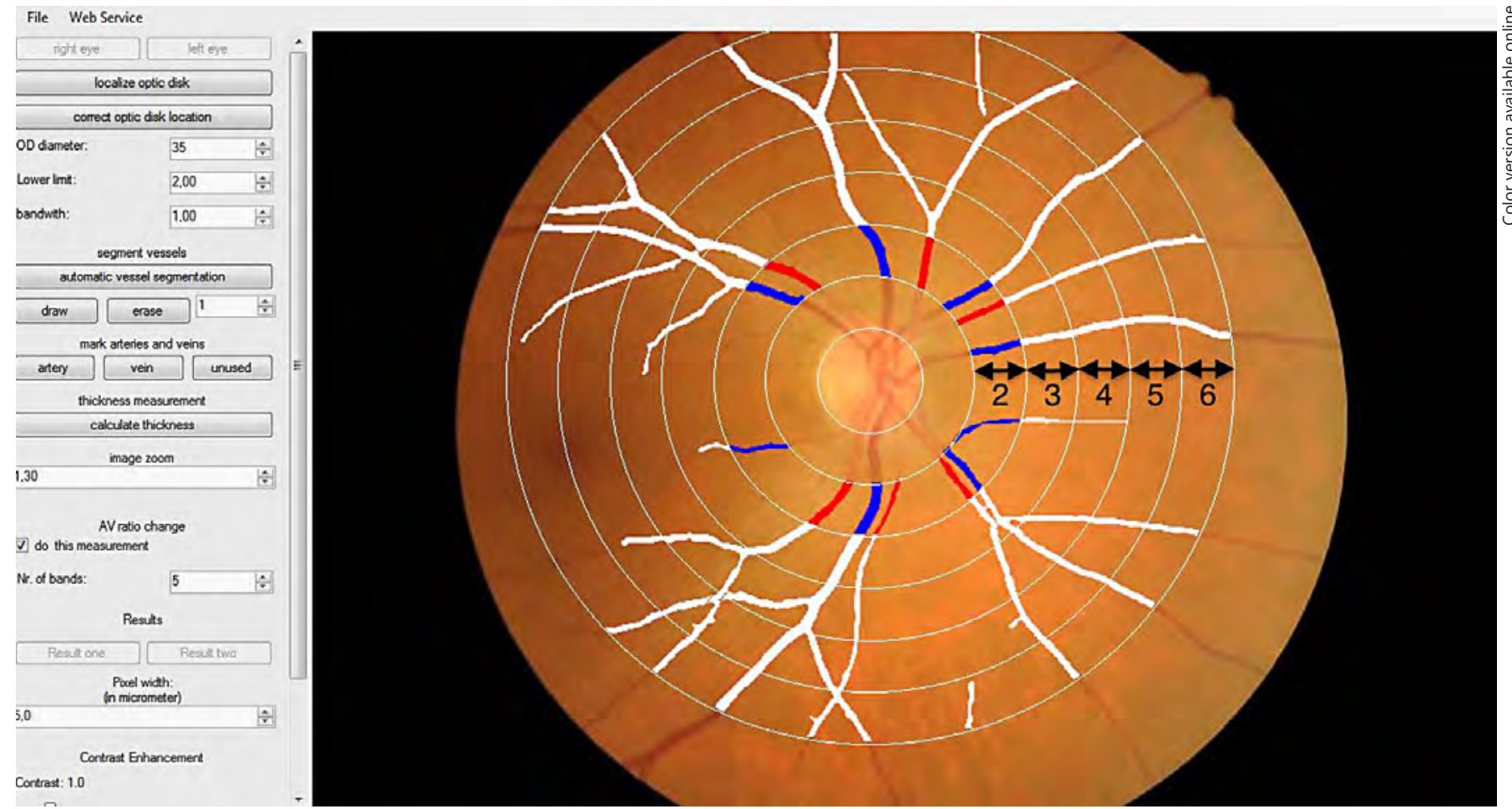

Fig. 1. Scheme of the software VesselThicknessMeasurement ${ }^{\odot}$. Retinal photograph and automated vessel analysis of the right eye of a subject with stroke within 1 year. Retinal vessels were segmented in 7 rings surrounding the optic disk. The edge of ring 2 is $0.5-$ 1.0 disk diameters from the optic disk margin. Arterioles and ve- nules in band 2 were marked by the grader. Calculations of the retinal vessel density are performed in bands 3-7. Retinal vascular density resembles the ratio of area of pixels lying on segmented vessels and of pixels of the ring area in percent. The rings 2-6 are represented with double arrows. prevalence of retinal microangiopathic abnormalities compared with age-matched "healthy" controls [3]. Due to the fact that the retinal and cerebral vessel systems share embryological, anatomical, and physiological characteristics, both show similar pathophysical attributes $[6$, 7]. Thus, the retinal capillary bed is thought to especially mirror cerebral microvascular changes. Pathophysiologically, vascular endothelial changes can lead to breakdown of autoregulation in the retinal and cerebral capillary systems [6-9].

Previously developed quantitative methods by using a semiautomated computer-based program to analyze the retinal circulation add to the clinical ophthalmologic examination. First efforts to evaluate the retinal vascular system with quantitative parameters have been reported $[5,10,11]$.

The effect of age and impaired cerebral circulation on retinal microcirculation requires further exploration. Therefore, we tested an applicable technique based on retinal color image evaluation. The aim of our efforts was to introduce the new parameter of retinal vascular density determined (RVD) by a semiautomated, computerbased program.

Photography of the posterior pole and the documentation of relevant medical information were performed by the tele-ophthalmic consultation service Talkingeyes ${ }^{\circledR}$.

Firstly, we aimed to evaluate the association of RVD and age. Secondly, we examined RVD in subjects with stroke and in age-matched nondiabetic, normotensive subjects without any systemic or ocular disease. In addition, we analyzed the effect of gender, arterial hypertension, and diabetes on RVD in stroke subjects.

\section{Materials and Methods}

\section{Design}

This study was performed in collaboration between the Department of Ophthalmology at the University Hospital Erlangen and the Center for Stroke Research, Charité Universitätsmedizin Berlin, Campus Benjamin Franklin. The technical element of our in- 
vestigations was supported by the Pattern Recognition Lab and Graduate School in Advanced Optical Technologies (SAOT), Friedrich-Alexander University Erlangen-Nürnberg. The Ethics Committee Charité Berlin provided approval for this medical research (approval No. EA2/084/11). The study was registered at the trial registration (clinicaltrials.gov, No. NCT01586702) and performed in accordance with the Declaration of Helsinki.

\section{Study Population}

These data and images are based on examinations gained by the tele-ophthalmic consultation service Talkingeyes ${ }^{\circledR}$ within the years 2007-2015. All participants underwent a medical interview that included general medical, ocular medical, and family history. Age, gender, presence of arterial hypertension, diabetes mellitus or any other systemic diseases, and incident stroke were registered [12].

We selected a group of $n=1,250$ "healthy" individuals aged 40-89 years, without arterial hypertension, diabetes mellitus, or any other ocular or systemic disease or stroke or heart infarction in medical history. Additionally all patients with nicotine abuse, glaucoma, one eye missing, and images with an inadequate image quality were excluded. A population of $n=592$ men and $n=658$ women met these requirements. The "stroke" group consisted of $n=158$ subjects, among them $n=96$ men and $n=62$ women; age ranged from 41 to 90 years $(56.78 \pm 10.8$ years $)$. All of those had suffered from minor stroke or transient ischemic attack within 1 year at the time of the examination, confirmed by the Neurological Department of the Charité Berlin.

Digital retinal images of both eyes were taken with a 45-degree nonmydriatic color fundus camera (KOWA NM-45, nonmydriatic-alpha) focused on the optic nerve head region. Photographing was done without dilatation of pupils. Medical data and retinal images were stored on a server using the web-based software MedStage. The evaluation of the color fundus images was carried out by an experienced ophthalmologist who was masked to the diagnoses. Retinal vessel analysis was performed by the software VesselsThicknessMeasurement ${ }^{\circledR}$ (Budai A., Pattern Recognition Lab and Graduate School in Advanced Optical Technologies, Friedrich-Alexander University Erlangen-Nürnberg, Erlangen, Germany). The parameters arteriovenous ratio and the RVD in predetermined areas around the optic head were calculated by the program (Fig. 1). This work focuses on RVD.

The automated analysis consists of 4 steps. First the optic disk is localized automatically. The correct position of the optic disk head margin was facilitated by the option of modifying its position and diameter manually. Secondly retinal vessels were segmented in 7 rings surrounding the optic disk including arteries and veins. The edge of ring 1 is 0.5 disk diameters from the optic disk margin, and the edge of ring 2 is $0.5-1.0$ disk diameters from the optic disk margin. Next, the software recognized and segmented all retinal vessels with diameters $>40 \mu \mathrm{m}$ automatically via a multiscale algorithm [13]. Contrast and brightness could be enhanced to settle uneven image brightness. Arteries and veins were manually classified. For the calculation of the arteriovenous ratio [14], the grader masked the 6 most prominent arterioles and venules within ring 2 . The indices arteriovenous ratio and RVD in bands 3-7 were calculated. The RVD was defined as quotient of the number of pixels lying on segmented vessels and the total of pixels in the defined ring-shaped areas surrounding the optic disk. For statistical purposes, we only analyzed the right eye of a subject.

Retinal Vascular Density in Ageing and Stroke
Table 1. Retinal vascular density in stroke patients and healthy controls by age decades

\begin{tabular}{|c|c|c|c|c|c|c|c|}
\hline \multirow[t]{3}{*}{ Decade } & & \multicolumn{6}{|c|}{ Retinal vascular density } \\
\hline & & \multicolumn{3}{|c|}{ stroke group } & \multicolumn{3}{|c|}{ control group } \\
\hline & & $n$ & $\begin{array}{l}\text { mean, } \\
\%\end{array}$ & $\begin{array}{l}\mathrm{SD}, \\
\%\end{array}$ & $n$ & $\begin{array}{l}\text { mean } \\
\%\end{array}$ & $\begin{array}{l}\mathrm{SD}, \\
\%\end{array}$ \\
\hline \multirow{5}{*}{$\begin{array}{l}41-50 \\
\text { years }\end{array}$} & ring 3 & 10 & 12.38 & 2.10 & 471 & 12.39 & 2.09 \\
\hline & $\operatorname{ring} 4$ & 10 & 9.25 & 0.80 & 471 & 8.68 & 1.70 \\
\hline & ring 5 & 10 & 7.16 & 0.59 & 471 & 5.98 & 1.92 \\
\hline & ring 6 & 10 & 5.39 & 0.76 & 471 & 4.36 & 1.77 \\
\hline & ring 7 & 10 & 3.66 & 1.17 & 471 & 3.25 & 2.06 \\
\hline \multirow{5}{*}{$\begin{array}{l}51-60 \\
\text { years }\end{array}$} & ring 3 & 19 & 9.98 & 2.68 & 481 & 11.52 & 1.91 \\
\hline & $\operatorname{ring} 4$ & 19 & 7.55 & 1.82 & 481 & 8.07 & 1.65 \\
\hline & $\operatorname{ring} 5$ & 19 & 5.30 & 2.41 & 481 & 5.81 & 1.60 \\
\hline & ring 6 & 19 & 4.01 & 2.04 & 481 & 4.24 & 1.54 \\
\hline & ring 7 & 19 & 2.76 & 1.71 & 481 & 3.45 & 2.16 \\
\hline \multirow{5}{*}{$\begin{array}{l}61-70 \\
\text { years }\end{array}$} & ring 3 & 57 & 9.28 & 2.33 & 168 & 10.68 & 1.98 \\
\hline & ring 4 & 57 & 6.88 & 1.65 & 168 & 7.59 & 1.33 \\
\hline & ring 5 & 57 & 5.01 & 1.84 & 168 & 5.52 & 1.54 \\
\hline & ring 6 & 57 & 3.63 & 1.84 & 168 & 4.05 & 1.76 \\
\hline & ring 7 & 57 & 2.03 & 1.59 & 168 & 2.67 & 2.22 \\
\hline \multirow{5}{*}{$\begin{array}{l}71-80 \\
\text { years }\end{array}$} & ring 3 & 60 & 8.71 & 2.26 & 97 & 10.38 & 1.67 \\
\hline & ring 4 & 60 & 6.34 & 1.81 & 97 & 7.37 & 1.67 \\
\hline & ring 5 & 60 & 4.61 & 1.49 & 97 & 5.35 & 1.36 \\
\hline & ring 6 & 60 & 3.32 & 1.32 & 97 & 3.37 & 1.26 \\
\hline & ring 7 & 60 & 1.95 & 1.35 & 97 & 1.64 & 1.29 \\
\hline \multirow{5}{*}{$\begin{array}{l}81-90 \\
\text { years }\end{array}$} & ring 3 & 12 & 8.49 & 1.84 & 33 & 8.93 & 1.50 \\
\hline & ring 4 & 12 & 6.14 & 2.22 & 33 & 6.64 & 1.73 \\
\hline & ring 5 & 12 & 4.21 & 1.43 & 33 & 5.22 & 0.74 \\
\hline & ring 6 & 12 & 2.49 & 1.25 & 33 & 3.27 & 1.02 \\
\hline & ring 7 & 12 & 1.22 & 0.55 & 33 & 1.35 & 1.36 \\
\hline
\end{tabular}

$n$, number of patients; SD, standard deviation. Retinal vascular density resembles ratio of area of pixels lying on segmented vessels and of pixels of the ring area in percent.

\section{Statistical Analysis}

Statistical analysis was performed by using the SPSS Statistics 23.0 software (IBM-SPAA, Chicago, IL, USA). Both "stroke" and "healthy" groups were divided into 5 decades of age (41-50, 51-60, $61-70,71-80,81-90$ years). Continuous variables were expressed as mean \pm standard deviation. A $p$ value $<0.05$ was considered to be statistically significant. To test the reliability of the software 12 fundus images of 12 eyes of 12 patients were analyzed 5 times. A Spearman correlation test was used for asymmetrically distributed continuous variables. Furthermore, a Mann-Whitney U test (nonparametric test) was performed comparing the index of RVD in stroke patients and controls by decades. To test the influence of 
potential cofactors on RVD, we extended our analysis to gender, blood pressure, and diabetes in stroke patients' medical history. A multiple regression was run to predict RVD from age, gender, stroke, hypertension, and diabetes.

\section{Results}

\section{Reliability}

The measurement of RVD of $n=12$ photographs of $n=12$ patients was performed 5 times by the same grader. This resulted in a reliability of the software of $r=0.91$.

\section{$R V D$ and Age}

In the control group we found a statistically significant correlation of the RVD in defined areas around the optic disk with age $\left(r=0.446, R^{2}=0.199, p=0.000\right)$.

Detailed information about the RVD per decades in the stroke and healthy control groups is given in Table 1 .

In both groups the mean retinal vascular index dwindled with increasing age.

The RVD of the stroke group decreased significantly with age. The strongest age-dependent decrease in RVD was found from age 41-50 to age 51-60. In the age group of 51-60 years there was a significant difference between the control and stroke groups in band $3(p=0.012)$, in the group of $71-80$ years in band $4(p=0.002)$ and band 5 $(p=0.007)$. The group of $81-90$ years showed a significant difference when regarding band $5(p=0.021)$ and band 6 $(p=0.033)$.

\section{Retinal Vascular Index in Patients with Stroke \\ Cofactor Age}

Patients with stroke showed in all rings significantly lower levels of mean RVD, on average by $15 \%$ compared to age-matched controls ( $p=0.046)$ (Fig. 2).

The stroke group revealed decreased vessel density by $-11 \%$ in the 5 th decade of age, $-12 \%$ in the 6 th and $-10 \%$ in the 7 th and 8 th decades compared to age-matched controls. The strongest decrease in vessel density by age was found in stroke patients from the 4 th to the 5 th decade (Fig. 3a, b).

In both groups, we found a decreasing RVD with increasing distance from the optic nerve head. The RVD of controls decreases significantly from band 3 (mean RVD $=11.58)$ to band 7 (mean RVD = 3.08) (Fig. 2).

\section{Cofactor Sex}

Male patients who suffered from stroke had a smaller RVD than did female patients, without reaching the level

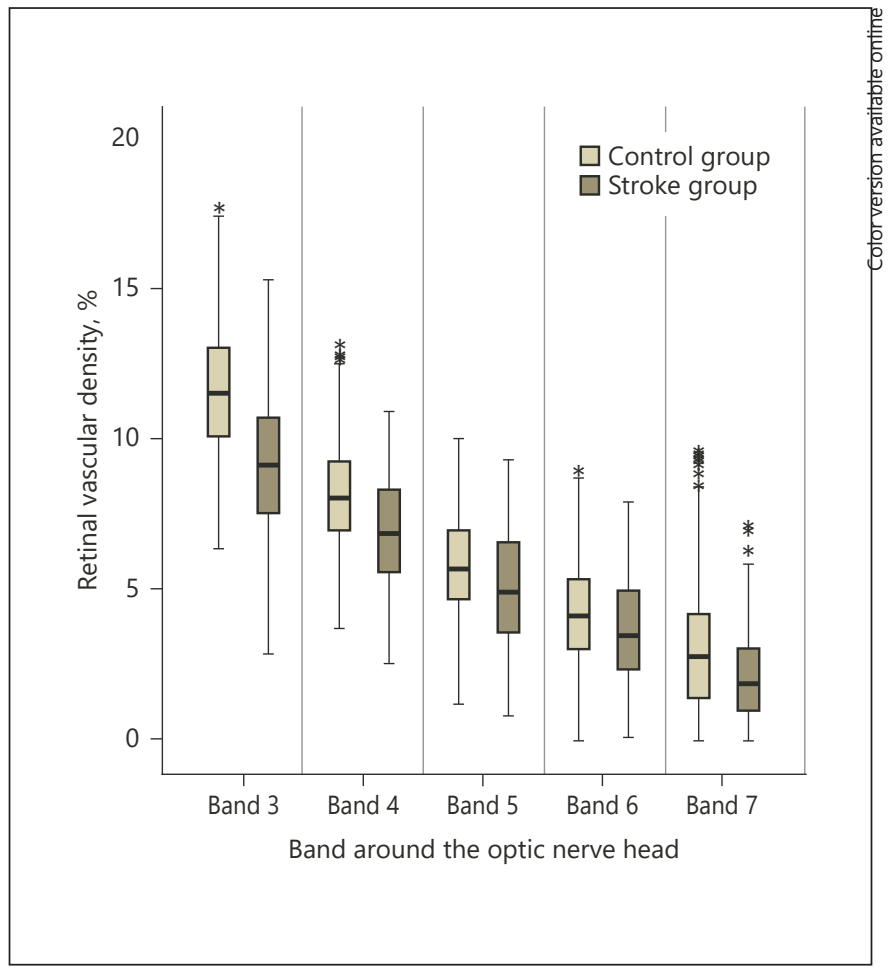

Fig. 2. Retinal vascular density around the optic nerve head in agematched controls and the stroke group. Retinal vascular density of both groups decreases with increasing distance from the optic disk location. Retinal vascular density of the control group decreases from 11.58 in band 3 to 3.08 in band 7. In the stroke group, the retinal vascular density decreases from 9.29 in band 3 to 2.13 in band 7.

of significance in the groups aged $41-50$ years $(p=0.31)$, $51-60$ years $(p=0.31), 61-70$ years $(p=0.26)$, and $81-90$ years $(p=0.45)$ (Table 2$)$. However, the RVD of male patients aged $71-80$ years was significantly $(p=0.007)$ decreased compared to females.

\section{Cofactor Hypertension}

We repeated analyses in stroke patients with hyperten$\operatorname{sion}(n=140)$.

Multivariate regression analysis of the RVD in the stroke group and systemic hypertension indicated no significant correlation in the following groups: 41-50 years $(p=0.57), 51-60$ years $(p=0.86)$, and $61-70$ years $(p=0.46)$ (Table 3$)$. The group of 71 - to 80 -year-old normotensives revealed significant higher levels of RVD than those with hypertension $(p=0.013)$. In the group of 81-90 years, all patients suffered from systemic hypertension.
Sprödhuber/Wolz/Budai/Laumeier/ Audebert/Michelson 


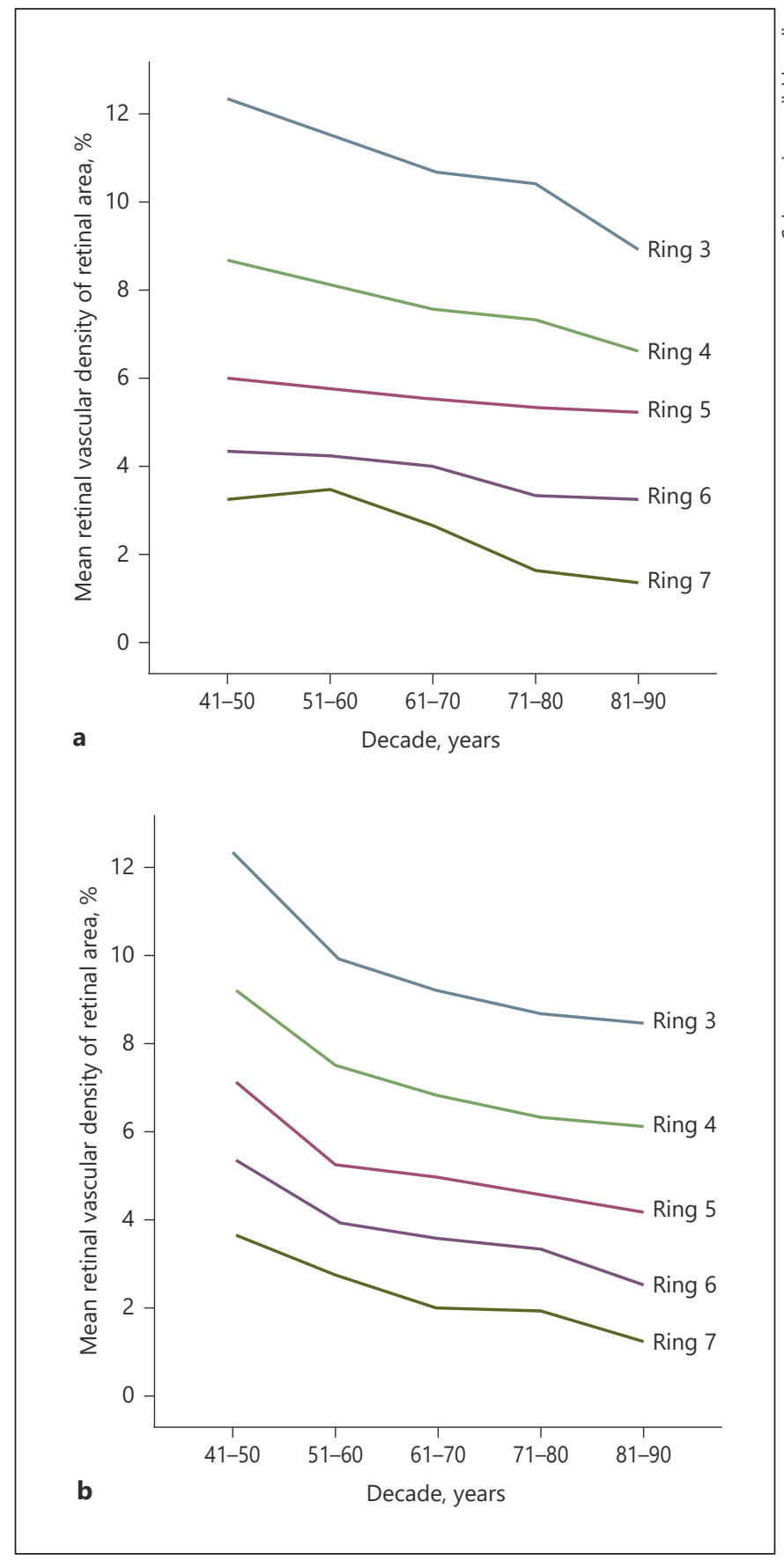

Fig. 3. a Retinal vascular density in controls by age decades. In the "healthy" controls, retinal vascular density in defined areas around the optic disk significantly decreased with increasing age. Retinal vascular density was calculated by the ratio of pixels on vessels and pixels of the ring area. $\mathbf{b}$ Retinal vascular density in patients with stroke by age decades. In the stroke group, the retinal vascular density was higher in young subjects. The strongest decrease in vessel density by age was found from the 4 th to the 5 th decade.
Table 2. Retinal vascular density in stroke patients by gender

\begin{tabular}{|c|c|c|c|c|c|c|}
\hline Decade & $\begin{array}{l}\text { Patients with } \\
\text { stroke, } n\end{array}$ & $\begin{array}{l}\text { Gen- } \\
\text { der }\end{array}$ & $n$ & $\begin{array}{l}\text { Mean } \\
\text { RVD, \% }\end{array}$ & $\begin{array}{l}\mathrm{SD} \\
\%\end{array}$ & $\begin{array}{l}p \\
\text { value }\end{array}$ \\
\hline \multirow[t]{2}{*}{$41-50$ years } & \multirow[t]{2}{*}{10} & $\mathrm{f}$ & 4 & 12.83 & 2.12 & \multirow[t]{2}{*}{0.31} \\
\hline & & $\mathrm{m}$ & 6 & 12.09 & 2.24 & \\
\hline \multirow[t]{2}{*}{$51-60$ years } & \multirow[t]{2}{*}{19} & $\mathrm{f}$ & 6 & 10.40 & 2.18 & \multirow[t]{2}{*}{0.31} \\
\hline & & $\mathrm{m}$ & 13 & 9.79 & 2.95 & \\
\hline \multirow[t]{2}{*}{$61-70$ years } & \multirow[t]{2}{*}{57} & $\mathrm{f}$ & 22 & 9.55 & 2.83 & \multirow[t]{2}{*}{0.26} \\
\hline & & $\mathrm{m}$ & 35 & 9.11 & 1.99 & \\
\hline \multirow[t]{2}{*}{$71-80$ years } & \multirow[t]{2}{*}{60} & $\mathrm{f}$ & 25 & 9.54 & 2.13 & \multirow[t]{2}{*}{0.007} \\
\hline & & $\mathrm{m}$ & 35 & 8.12 & 2.2 & \\
\hline \multirow[t]{2}{*}{$81-90$ years } & \multirow[t]{2}{*}{12} & $\mathrm{f}$ & 5 & 8.58 & 2.3 & \multirow[t]{2}{*}{0.45} \\
\hline & & $\mathrm{m}$ & 7 & 8.45 & 1.6 & \\
\hline
\end{tabular}

$n$, number of patients; RVD, retinal vascular density; SD, standard deviation.

Table 3. Retinal vascular density in hypertensive stroke patients versus normotensive stroke patients

\begin{tabular}{llll}
\hline Decade, years & $\begin{array}{l}\text { Patients with } \\
\text { stroke, } n\end{array}$ & $\begin{array}{l}\text { Patients with } \\
\text { hypertension, } n\end{array}$ & $p$ value \\
\hline 41-50 years & 10 & $\begin{array}{l}\text { yes: } 7 \\
\text { no: } 3 \\
\text { yes: } 12 \\
\text { no: } 7 \\
\text { yes: } 52 \\
\text { no: } 5\end{array}$ & 0.57 \\
61-60 years & 19 & $\begin{array}{l}\text { yes: } 57 \\
\text { no: } 3 \\
\text { yes } 12 \\
\text { no: } 0\end{array}$ & 0.86 \\
$71-80$ years & 57 & 12 & 0.013 \\
$81-90$ years & 12 & n.a. \\
\hline
\end{tabular}

$n$, number of patients; n.a., not available; $p$ value significant at the $p<0.05$ level.

Table 4. Retinal vascular density in stroke patients with diabetes versus stroke patients without diabetes

\begin{tabular}{|c|c|c|c|}
\hline Decade & $\begin{array}{l}\text { Patients with } \\
\text { stroke, } n\end{array}$ & $\begin{array}{l}\text { Patients with } \\
\text { diabetes, } n\end{array}$ & $p$ value \\
\hline $51-60$ years & 19 & $\begin{array}{l}\text { yes: } 5 \\
\text { no: } 14\end{array}$ & 0.01 \\
\hline $61-70$ years & 57 & $\begin{array}{l}\text { yes: } 7 \\
\text { no: } 50\end{array}$ & 0.54 \\
\hline $71-80$ years & 60 & $\begin{array}{l}\text { yes: } 9 \\
\text { no: } 51\end{array}$ & 0.75 \\
\hline $81-90$ years & 12 & $\begin{array}{l}\text { yes } 7 \\
\text { no: } 5\end{array}$ & 0.35 \\
\hline
\end{tabular}

$n$, number of patients; $p$ value significant at the $p<0.05$ level. 
Table 5. Multiple linear regression model of retinal vascular density in band 3

Model summary

\begin{tabular}{lllll}
\hline Model & $R$ & $R^{2}$ & Adjusted $R^{2}$ & SEE \\
\hline 1 & $0.482^{\mathrm{a}}$ & 0.232 & 0.229 & 0.02004428 \\
\hline
\end{tabular}

ANOVA $^{\mathrm{b}}$

\begin{tabular}{llllll}
\hline Model & & Sum of squares & df & Mean square & $F$ \\
\hline 1 & regression & 0.170 & 5 & 0.034 & 84.804 \\
& residual & 0.563 & 1,402 & 0.000 & $0.000^{\mathrm{a}}$ \\
& total & 0.734 & 1,407 & & \\
\hline
\end{tabular}

\section{Coefficients $^{\mathrm{b}}$}

\begin{tabular}{|c|c|c|c|c|c|c|}
\hline Model & & $\begin{array}{l}\text { Unstandardized, } \\
\text { B }\end{array}$ & $\begin{array}{l}\text { Coefficients, } \\
\text { SE }\end{array}$ & $\begin{array}{l}\text { Standardized } \\
\text { coefficients } \beta\end{array}$ & $t$ & Sig. \\
\hline \multirow[t]{6}{*}{1} & (constant) & 0.126 & 0.009 & & 14.210 & 0.000 \\
\hline & age & -0.008 & 0.001 & -0.384 & -15.107 & 0.000 \\
\hline & gender & 0.004 & 0.001 & 0.095 & 4.048 & 0.000 \\
\hline & stroke & 0.012 & 0.005 & 0.162 & 2.423 & 0.016 \\
\hline & hypertension & 0.000 & 0.005 & 0.006 & 0.096 & 0.923 \\
\hline & diabetes & -0.001 & 0.004 & -0.004 & -0.153 & 0.878 \\
\hline
\end{tabular}

SEE, standard error of the estimate; SE, standard error; sig., significance. ${ }^{\text {a }}$ Predictors: 1 (constant), diabetes, gender, age, hypertension, stroke. ${ }^{\mathrm{b}}$ Dependent variable: retinal vascular density in band 3.

\section{Cofactor Diabetes}

We could not find a significant correlation of RVD in diabetics with stroke and stroke patients aged 61-90 years without diabetes (Table 4). Compared to patients without diabetes, diabetics did not have significantly lower values of RVD. Statistical analysis resulted in the following $p$ values: $p=0.52$ (61-70 years), $p=0.75$ (71-80 years), and $p=0.35$ (81-90 years). Conversely, the group of 51- to 60 -year-old diabetic stroke patients showed significantly lower levels of RVD than those without diabetes in their medical history $(p=0.01)$.

Multiple linear regression analysis was used to develop a model for predicting RVD from age, gender, stroke, hypertension, and diabetes. Basic descriptive statistics and regression coefficients are shown in Table 5 . All variables significantly predicted RVD in band 3, with $F(5,1,402)=$ $84,504, p<0.005$. Age, gender, and stroke added statistically significantly to the prediction $(p<0.05)$, whereas hypertension and diabetes did not reach the level of significance.

\section{Discussion}

Several studies have focused on the relationship between microvascular cerebral alterations and ageing. Besides a reduction of cerebral blood flow, the ageing brain shows a decreased glucose and oxygen metabolism [1517]. Similarly, it has been revealed that the retinal blood flow and metabolic demand decrease incrementally with age $[18,19]$.

Riddle et al. [20] analyzed 22 studies and showed a decline of cerebral vascular density with age. Buée et al. [21] reported that the vascular density of the brain in 2 normal subjects aged 79 years compared to 1 young subject aged 49 years was decreased by $26 \%$.

Powers and Zazulia [22] revealed that the assessment of the cerebral vasculature is important in determining an individual's risk of particular cerebrovascular diseases, such as stroke.

The relationship of the cerebral and retinal microcirculation systems suggests that funduscopic examination 
or retinal photography is a useful and fast method to perform risk stratifications of cerebrovascular diseases at ophthalmological routine examinations [6-8].

As retinal vascular changes reflect specific cerebral microvasculopathy, our findings seem to confirm findings from earlier studies [23]. Data published in the Atherosclerosis Risk in Communities Study (ARIC) showed that persons with retinal vascular changes at baseline were 2to 3-fold more likely to develop an incident clinical stroke [24]. Arteriovenous nicking, focal arteriolar narrowing, microaneurysms, a decreased arteriovenous ratio, and larger retinal venular caliber have been shown to be associated with an increased risk for stroke [25]. Our data showed that patients with stroke have a decreased RVD analyzing the posterior pole. The RVD calculated by the ratio area of vessels per area of retina resembles an additional aspect to quantify retinal microvascular structure.

The retinal vascular area in the stroke group showed significant lower values of vessel area in defined areas surrounding the optic disk compared to age-matched healthy controls. The retinal vascular density measured in band 3 averaged out $11.6 \%$ in controls and $9.3 \%$ in stroke patients. This means that in age-matched stroke patients the vascular density is decreased by $20 \%$ corresponding to data of Buée et al. [21]. The RVD of the stroke group resulted in $15.9 \%$ lower vascular density in band $4,14.1 \%$ lower values in band 5, 14\% lower values in band 6 , and $30.6 \%$ lower values in band 7 . The greatest gradient to controls was found in the stroke group aged 51-60 years. We showed that RVD decreased towards the retinal periphery.

Secondly, we found a significant correlation of the RVD and age. Both control and stroke group revealed a significant decline of RVD with increasing decades. In the stroke group, RVD was significantly lower than in agematched controls.

Our findings are in accordance with earlier data published by Ciulla et al. [6] in 2000, who carried out a computerized analysis of digitized photos of the fundus oculi in circular areas around the optic disk. They found that RVD in 68 nonsmoking, normotensive normal subjects was significantly related to age. Both the retinal and the cerebral microvascular systems sustain similar changes with ageing [6].

Additionally, this analysis revealed that there is no significant difference between the RVD in hypertensive stroke patients and normotensive stroke patients aged 41-70 years. Conversely, we found significance in older hypertensive subjects. The same applies to the RVD in male and female patients with apoplexy. Only middle- aged subjects with diabetes and stroke showed a significant decrease in RVD.

Progress in retinal automated retinal vascular imaging technologies has provided clinicians and researchers with noninvasive means to measure and quantify abnormalities in the retinal microvasculature. However, further work is needed to improve photography, as the segmented vessels used for our calculation depend on image quality.

Limitations of our retrospective study include that retinal vascular density depends on image quality. Any photographs that were not of sufficient quality were excluded.

\section{Conclusion}

The newly developed image-analyzing program allowed measurements of RVD using 45-degree color images of the retina with a good reliability. The area of retinal vessels significantly decreased with age. In patients with recent stroke the RVD was significantly reduced compared to age-matched healthy controls. Hypertension and stroke are associated with significantly decreased RVD in old subjects whereas diabetes and stroke are associated with significantly decreased RVD in middleaged subjects. These findings could be useful for clinical monitoring as a reduced RVD is a manifestation of hypertensive microangiopathy. RVD is a new parameter for noninvasive medical evaluation of vessel network without dependence on other parameters. Prospectively, RVD may be useful in identifying early changes in the retinal vascular system during ageing and in patients with cerebrovascular disease.

\section{Disclosure Statement}

The authors state that there are no conflicts of interest.

\begin{tabular}{|c|c|}
\hline eferences & $\begin{array}{l}\text { Cheung CY, Ikram MK, Sabanayagam C, et al: } \\
\text { Retinal microvasculature as a model to study } \\
\text { the manifestations of hypertension. Hyper- } \\
\text { tension 2012;60:1094-1103. } \\
2 \text { American Heart Association: Coronary mi- } \\
\text { crovascular disease (MVD). 2016. www.heart. } \\
\text { org/HEARTORG/Conditions/HeartAttack/ } \\
\text { DiagnosingaHeartAttack/Coronary-Micro- } \\
\text { vascular-Disease-MVD_UCM_450320_Arti- } \\
\text { cle.jsp. } \\
3 \text { Wolz J, Audebert H, Laumeier I, et al: Tele- } \\
\text { medical assessment of optic nerve head and } \\
\text { retina in patients after recent minor stroke or } \\
\text { TIA. Int Ophthalmol 2017;37:39-46. }\end{array}$ \\
\hline
\end{tabular}


4 Yamamoto Y, Marugame A, Ogura M, et al: Age-decreases of the retinal vasculature area identified with a novel computer-aided analysis system. Tohoku J Exp Med 2012;228:229_ 237.

$>5$ Kim DH, Grodstein F, Newman AB, et al: Prognostic implications of microvascular and macrovascular abnormalities in older adults: Cardiovascular Health Study. J Gerontol A Biol Sci Med Sci 2014;69:1495-1502.

6 Ciulla MM, Tortora G, Valentini P, et al: Vascular network changes in the retina during ageing in normal subjects: a computerized quantitative analysis. Ital Heart J 2000;1:361364.

$>7$ Wong TY, Klein R, Klein BEK et al: Retinal micovascular abnormalities and their relationship with hypertension, cardiovascular diseases and mortality. Surv Ophthalmol 2001;46:59-80.

$>8$ Goto I, Katsuki S, Ikui H, et al: Pathological studies on the intracerebral and retinal arteries in cerebrovascular and noncerebrovascular diseases. Stroke 1975;6:263-269.

$>9$ Wong TY, Klein R, Sharrett AR, et al: Cerebral white matter lesions, retinopathy, and incident clinical stroke. JAMA 2002;288:67-74.

10 Patton N, Aslam T, Macgillivray T, et al: Retinal vascular image analysis as a potential screening tool for cerebrovascular disease: a rationale based on homology between cerebral and retinal microvasculatures. J Anat 2005;206:319-348
$>11$ Wong TY, Klein R, Couper DJ, et al: Retinal microvascular abnormalities and incident stroke: the Atherosclerosis Risk in Communities Study. Lancet 2001;358:1134-1140.

$>12$ Michelson G, Groh M, Groh MJ, et al: Telemedical-supported screening of retinal vessels ("talkingeyes"). Klin Monbl Augenheilkd 2005;222:319-325.

13 Budai A, Michelson G, Hornegger J: Multiscale approach for blood vessel segmentation in retinal fundus Images. Invest Ophthalmol Vis Sci 2009;50:325.

14 Hubbard LD, Brothers RJ, King WN, et al Methods for evaluation of retinal microvascular abnormalities associated with hypertension/sclerosis in the Atherosclerosis Risk in Communities Study. Ophthalmology 1999; 106:2269-2280

15 Fabiani M, Low KA, Tan CH, et al: Taking the pulse of aging: mapping pulse pressure and elasticity in cerebral arteries with optical methods. Psychophysiology 2014;51:10721088.

-16 Hoyer S: Brain glucose and energy metabolism during normal aging. Aging (Milano) 1990;2:245-258.

17 Ances BM, Liang CL, Leontiev O, et al: Effects of aging on cerebral blood flow, oxygen metabolism, and blood oxygenation level dependent responses to visual stimulation. Human Brain Mapp 2009;30:1120-1132.
18 Embletion SJ, Hosking SL, Roff Hilton EJ, et al: Effect of senescence on ocular blood flow in the retina, neuroretinal rim and lamina cribrosa, using scanning laser Doppler flowmetry. Eye (Lond) 2002;16:156-162.

19 David J: Calkings: age-related changes in the visual pathways: blame it on the axon. Invest Ophthalmol Vis Sci 2013;54:ORSF37ORSF41.

20 Riddle DR, Sonntag WE, Lichtenwalner RJ: Microvascular plasticity in aging. Ageing Res Rev 2003;2:149-168.

21 Buée L, Hof PR, Bouras C, et al: Pathological alterations of the cerebral microvasculature in Alzheimer's disease and related dementing disorders. Acta Neuropathol 1994;87:469480.

22 Powers WJ, Zazulia AR: PET in cerebrovascular disease. PET Clin 2010;5:83-106.

23 Lindley RI, Wang JJ, Wong MC, et al; MultiCentre Retina and Stroke Study (MCRS) Collaborative Group: Retinal microvasculature in acute lacunar stroke: a cross-sectional study. Lancet Neurol 2009;8:628-634.

24 Cooper LS, Wong TY, Klein R, et al: Retinal microvascular abnormalities and MRI-defined subclinical cerebral infarction: the Artherosclerosis Risk in Communities Study. Stroke 2006;37:82-86.

25 Baker ML, Hand PJ, Wang JJ, et al: Retinal signs and stroke: revisiting the link between the eye and brain. Stroke 2008;39:1371-1379. 